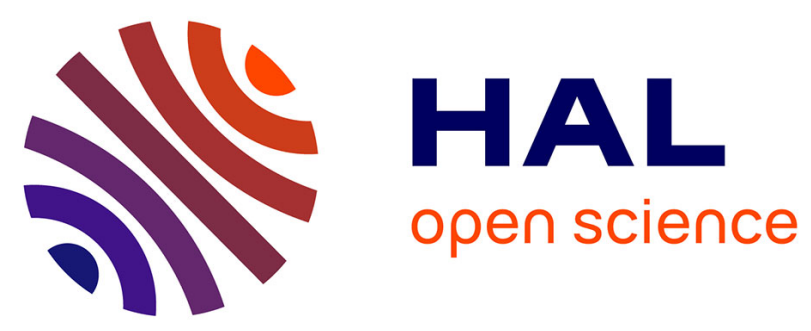

\title{
Prediction of Audible Magnetic Noise Radiated by Adjustable-Speed Drive Induction Machines
}

Jean Le Besnerais, Vincent Lanfranchi, Michel Hecquet, Pascal Brochet, Guy Friedrich

\section{To cite this version:}

Jean Le Besnerais, Vincent Lanfranchi, Michel Hecquet, Pascal Brochet, Guy Friedrich. Prediction of Audible Magnetic Noise Radiated by Adjustable-Speed Drive Induction Machines. IEEE Transactions on Industry Applications, 2010, 46 (4), pp.1367 - 1373. 10.1109/TIA.2010.2049624 . hal-01711185

\author{
HAL Id: hal-01711185 \\ https://hal.science/hal-01711185
}

Submitted on 16 Feb 2018

HAL is a multi-disciplinary open access archive for the deposit and dissemination of scientific research documents, whether they are published or not. The documents may come from teaching and research institutions in France or abroad, or from public or private research centers.
L'archive ouverte pluridisciplinaire HAL, est destinée au dépôt et à la diffusion de documents scientifiques de niveau recherche, publiés ou non, émanant des établissements d'enseignement et de recherche français ou étrangers, des laboratoires publics ou privés. 


\title{
Prediction of audible magnetic noise radiated by adjustable speed drive induction machines
}

\author{
Jean Le Besnerais, Vincent Lanfranchi, Michel Hecquet, Member, IEEE, Pascal Brochet Member, IEEE, Guy \\ Friedrich, Senior Member, IEEE.
}

\begin{abstract}
This paper presents a fully analytical model of the electromagnetic and vibro-acoustic behavior of variable-speed squirrel-cage induction machines. This model is integrated in a fast simulation tool that can be used to design motors with low magnetic noise level on their whole speed range.

Some simulation results at variable speed are favorably compared with experiments at both vibratory (spectrograms) and acoustic levels (sonagrams) on a $700 \mathrm{~W}$ laboratory motor and on an industrial $250 \mathrm{~kW}$ traction motor.

These extensive tests show that the model correctly predicts the main exciting forces, motor natural frequencies and resonances during adjustable-speed drive. The simulation tool, called DIVA, has been successfully applied to design a new low-noise ALSTOM motor.
\end{abstract}

\section{NOMENCLATURE}

$B_{g} \quad$ Air-gap radial flux density

$D_{\text {so }} \quad$ Stator stack inner diameter

$E_{s} \quad$ Stator core young modulus

$f_{m m} \quad$ Magnetomotive force

$f_{\max }$ Maximum supply frequency

$f_{n} \quad n$-th circumferential mode natural frequency

$f_{R} \quad$ Rotor mechanical frequency $\left(f_{R}=f_{s}(1-s) / p\right)$

$f_{s} \quad$ Fundamental stator supply frequency

$h_{f} \quad$ Height of frame

$h_{s y} \quad$ Stator height of yoke

$m \quad$ Spatial order of a force harmonic

$n \quad n$-th stator circumferential mode

$p \quad$ Number of pole pairs

$q_{s} \quad$ Number of stator phases

$R_{s i} \quad$ Stator stack inner radius

$R_{s y} \quad$ Stator yoke mean radius

$s \quad$ Fundamental slip

$Z_{r} \quad$ Number of rotor slots

$Z_{s} \quad$ Number of stator slots

$\Lambda \quad$ Air-gap permeance per unit area

$\mu_{0} \quad$ Air-gap magnetic permeability

\section{INTRODUCTION}

Acoustic noise is a factor that is no longer neglected during design stage of electrical machines, as much for its impact on safety in industrial environments than for its impact on acoustic comfort in electrical transport systems. Noise can be classified in three main sources [1]: mechanical source (bearings, gearbox, etc), aerodynamic source (fan, ventilation ducts, etc) and magnetic source. Magnetic noise is defined as noise coming from vibrations due to magnetic forces which include Maxwell and magnetostrictive forces. It can dominate
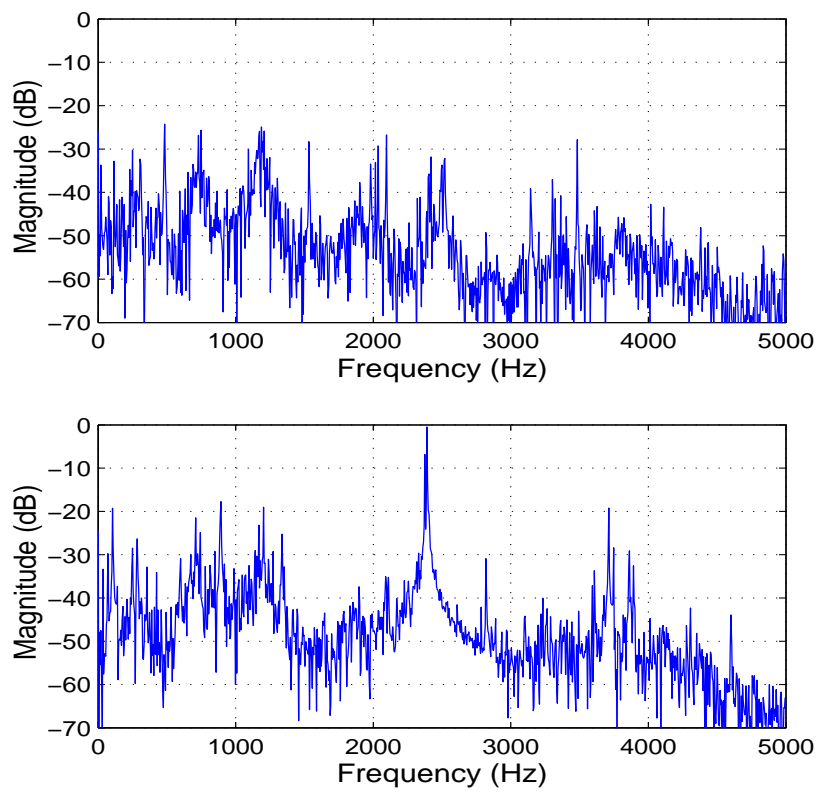

Fig. 1. Normalized vibration level spectrum at $f_{s}=40 \mathrm{~Hz}$ (top) and $f_{s}=75 \mathrm{~Hz}$ (bottom) of laboratory motor, sinusoidal case.

the motor global noise level, especially at low and medium speed where fan noise is less important, and it can contain unpleasantly high tonalities that are penalized by IEC 600349 norm. It is therefore important to be able to predict high magnetic noise levels in order to design low noise electrical machines.

Fig. I shows the vibration level recorded on an accelerometer sensor placed on the frame of a laboratory $700 \mathrm{~W}$ squirrelcage motor at two different speeds: the vibration level, which is mainly due to magnetic forces at frequencies greater than 500 $\mathrm{Hz}$, strongly depends on the stator fundamental frequency $f_{s}$ as a $30 \mathrm{~dB}$ increase is observed near $2400 \mathrm{~Hz}$ from $f_{s}=40 \mathrm{~Hz}$ to $75 \mathrm{~Hz}$. Indeed the distribution of magnetic forces along the air-gap can be represented by an infinite set of rotating force waves (harmonics [2] coming from the 2D Fourier transform of Maxwell radial forces) that can excite the stator structure natural frequencies [3]. As the speed of these traveling force waves is proportional to the stator fundamental frequency, some resonances can appear according to the motor speed value and its stator circumferential modes natural frequencies [4].

In this paper is presented a fully analytical model (DIVA) of the vibro-acoustic behavior of induction motors, taking 
into account the interaction between the exciting magnetic forces and the excited structure, and resonances that occur during accelerations and decelerations. This model is then validated on a wide power range (from $700 \mathrm{~W}$ to $250 \mathrm{~kW}$ ) at both acoustic and vibratory levels, using the sonagram and spectrogram representations.

\section{ElectromagnetiC AND VIBRO-ACOUSTIC MODELING}

The global effect of Maxwell forces on the stator can be brought to a Maxwell pressure distribution in the air-gap [5]. This pressure $P_{M}$ is purely radial on stator teeth, it can be approximated by [6], [7], [8]

$$
P_{M}=B_{g}^{2} /\left(2 \mu_{0}\right)
$$

where $B_{g}$ is the radial air-gap flux density. Assuming that the rotor is not skewed, and neglecting end-effects, this force distribution is independent of the motor axial direction. To determine the exciting forces, one must therefore compute the radial air-gap flux density. The analytical model DivA is composed of an electromagnetic model that computes the airgap flux density, and a vibro-acoustic model that computes the resulting magnetic forces and their impact on vibration and noise.

\section{A. Electromagnetic model}

Radial air-gap flux density $B_{g}$ can be decomposed as the product of permeance and magnetomotive force (mmf) following

$$
B_{g}\left(t, \alpha_{s}\right)=\Lambda\left(t, \alpha_{s}\right) f_{m m}\left(t, \alpha_{s}\right)
$$

where $\alpha_{s}$ is the angular position in the stator steady frame, $\Lambda=\mu_{0} / g_{e}$ is the air-gap permeance per unit area, $g_{e}$ being the effective air-gap magnetic width, $\mu_{0}$ the air-gap magnetic permeability and $f_{m m}$ is the total magnetomotive force. Applying the Ampere's law to an appropriate path, one can show [9] that

$$
f_{m m}\left(t, \alpha_{s}\right)=\underbrace{\sum_{q=1}^{q_{s}} i_{q}^{s}(t) N_{q}^{s}\left(\alpha_{s}\right)}_{f_{m m}^{s}}+\underbrace{\sum_{b=1}^{Z_{r}} i_{b}^{r}(t) N_{b}^{r}\left(t, \alpha_{s}\right)}_{f_{m m}^{r}}
$$

where $N_{q}^{s}$ is the 2-D turns function or winding distribution function associated to the stator $q$-th phase with current $i_{q}^{s}$, and $N_{b}^{r}$ is the turns function associated to the rotor $b$-th bar with current $i_{b}^{r}$. This turn function can be easily found from the winding pattern of the motor [10], [11].

The simulated distribution of stator and rotor $\mathrm{mmf}$, permance and flux density are displayed in Fig. 2 on a $250 \mathrm{~kW}$ ALSTOM motor.

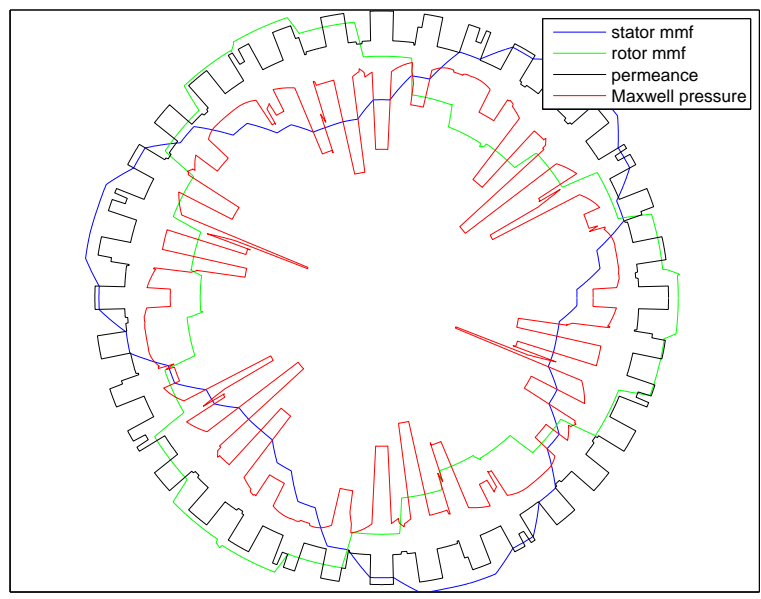

Fig. 2. Maxwell pressure, stator and rotor magnetomotive forces, and permeance distributions (industrial motor).
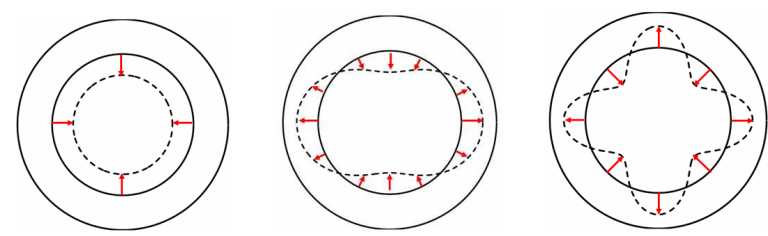

Fig. 3. Illustration of the electromagnetic force decomposition in several sinusoidal force waves (spatial orders 0,2 and 4). The magnitude, velocity, propagation direction of these elementary force waves are given by the 2D Fourier series of the air-gap electromagnetic pressure distribution.

\section{B. Vibro-acoustic model}

The magnetic pressure $B_{g}^{2} /(2 \mu 0)$ is first decomposed in 2D Fourier series to obtain a set of sinusoidal force waves of complex magnitude $P_{m \omega}$, spatial order $m$ and pulsation $\omega$ (see Fig. 3).

The static displacements under each sinusoidal load are then computed by modeling the stator structure as an equivalent ring. Static displacement associated to order 0 is [8]

$$
Y_{0 \omega}^{s}=P_{0 \omega} \frac{R_{s y} R_{s i}}{E_{s} h_{s y}}
$$

For orders $m \geq 2$, static deflections are expressed as

$$
Y_{m \omega}^{s}=P_{m \omega} \frac{12 R_{s i} R_{s y}^{3}}{E_{s} h_{s y}^{3}\left(m^{2}-1\right)^{2}}
$$

If we compare the static displacements of order $m>1$ to the zero-th order one, we get

$$
\frac{Y_{m \omega}^{s}}{Y_{0 \omega}^{s}} \propto \frac{P_{m \omega}}{P_{0 \omega}} \frac{1}{\left(m^{2}-1\right)^{2}} \frac{R_{s y}^{2}}{h_{s y}^{2}}
$$

The ratio $R_{s y} / h_{s y}$ therefore sizes the ability of the motor to generate high displacements of order $m>1$. Moreover, the higher is the spatial order, the lower is the displacement. This ratio has been plotted for different orders in Fig. 4.

Once static displacements are determined, one must compute dynamic displacement due to exciting forces. This can be done as a first approximation using a second order filter: 


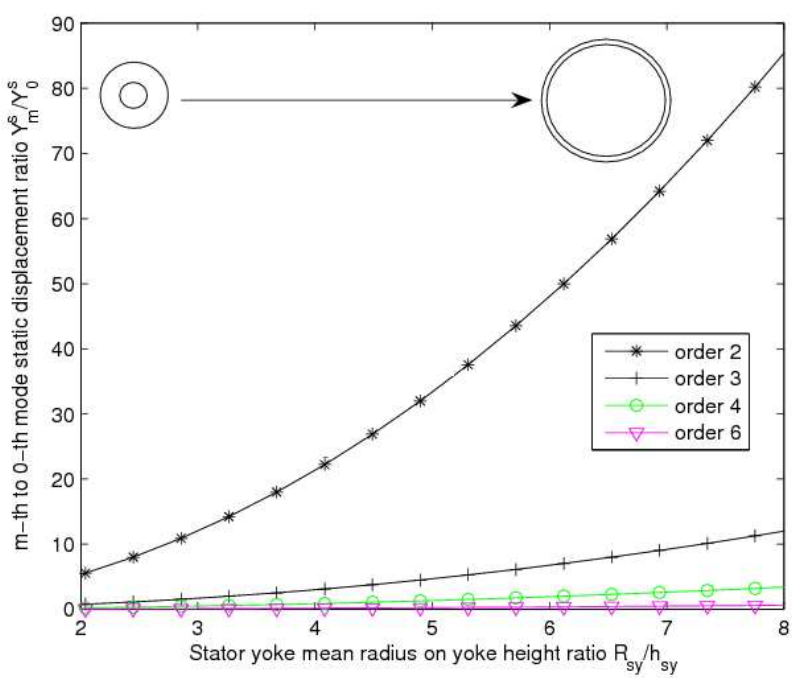

Fig. 4. Relative static displacement in function of $R_{s y} / h_{s y}$ ratio for several modes. Doubling the relative static displacement increases the sound power level at resonance of $10 \log _{10}\left(2^{2}\right) \approx 6 \mathrm{~dB}$.

$$
Y_{m \omega}^{d}=Y_{m \omega}^{s}\left[\left(1-f^{2} / f_{m}^{2}\right)^{2}+4 \xi_{m}^{2} f^{2} / f_{m}^{2}\right]^{-1 / 2}
$$

where $f_{m}$ is the $m$-th stator circumferential mode natural frequency, and $\xi_{m}$ is the corresponding modal damping coefficient that can be computed using the experimental law established by [12].

These dynamic displacements generate radial velocity vibration waves of magnitude $\omega Y_{m \omega}^{d}$. From the knowledge of these waves, the global vibration level can be determined [11], as well the global sound power level through a radiation efficiency model [13].

The stator circumferential modes natural frequencies are also computed by assimilating the stator to an equivalent ring [14]. The breathing mode natural frequency $f_{0}$ is given by

$$
f_{0}=\frac{1}{2 \pi a} \sqrt{\frac{E_{s}}{K_{f s} \Delta_{m} \rho_{s}}}
$$

where $a=\left(D_{s o}+h_{f}-h_{s y}\right) / 2$ is the stator mean radius taking into account the frame width $h_{f}, K_{f s}$ is the stator stacking factor, $\rho_{s}$ the stator stack mass density, and $\Delta_{m}$ is the mass increase due to winding and teeth:

$$
\Delta_{m}=1+\frac{W_{s t}+W_{s w}}{W_{f}+W_{s y}}
$$

where $W_{s t}, W_{s w}, W_{f}$ and $W_{s y}$ respectively stand for the mass of stator teeth, winding, frame and yoke.

For modes $m>1, f_{m}$ is computed as

$$
f_{m}=K_{m} f_{0} \frac{h}{2 \sqrt{3} a} \frac{m\left(m^{2}-1\right)}{\sqrt{m^{2}+1}}
$$

where $h=h_{s y}+h_{f}$, and $K_{m}$ is a corrective coefficient whose expression can be found in [14], [15], [16].
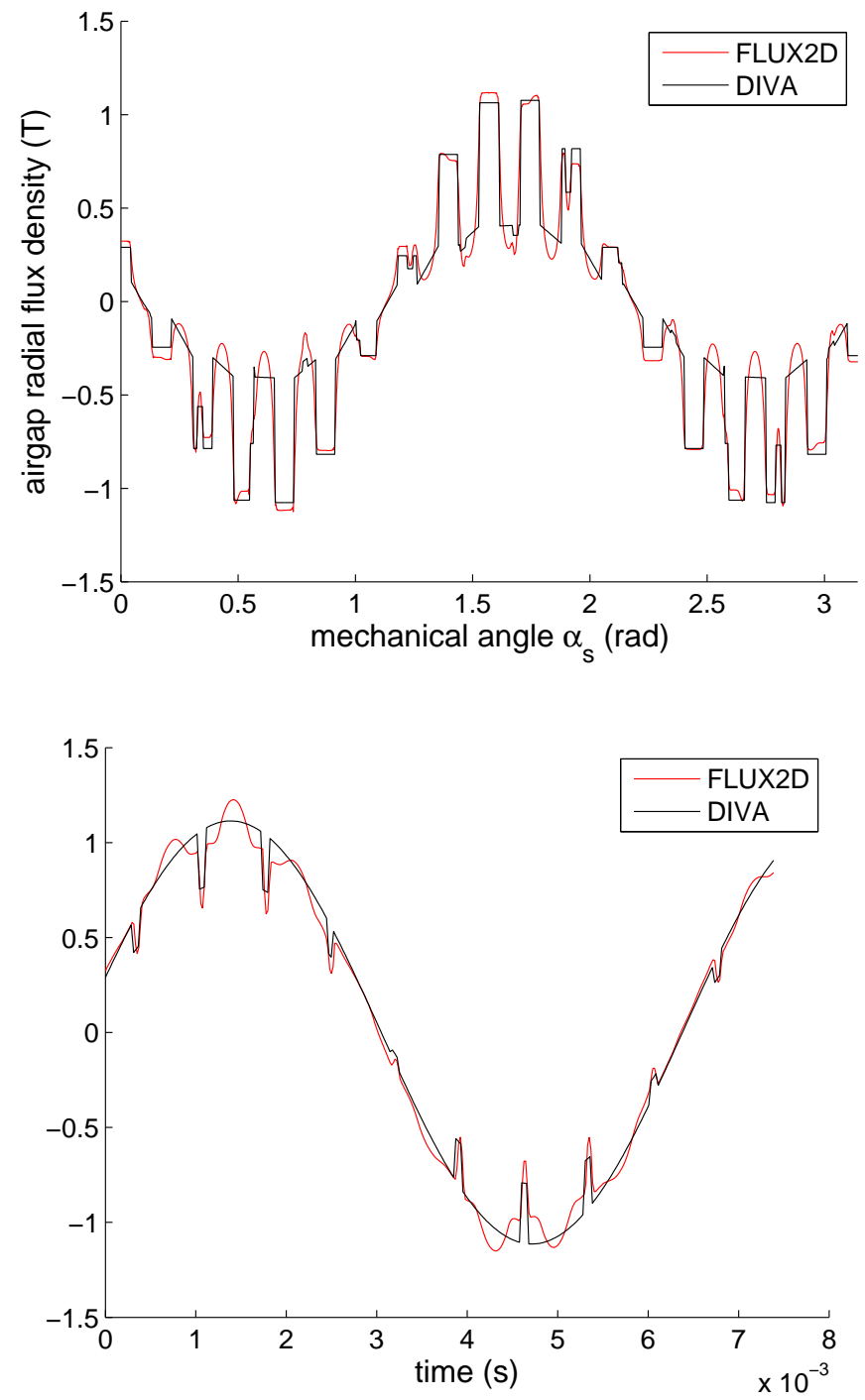

Fig. 5. FEM and analytical radial flux density distribution along the air-gap (top) and in function of time (bottom) (sinusoidal no-load case).

\section{VALIDATIONS}

\section{A. Electromagnetic model}

The electromagnetic model has been validated by comparing some finite element method (FEM) simulations with FLUX2D software with the analytical model simulations. As an example, Fig. 5 shows the validation on the air-gap radial flux density distribution in time and space on the $250 \mathrm{~kW}$ industrial motor.

\section{B. Vibro-acoustic model}

1) Natural frequencies: The natural frequencies of the stator of the $250 \mathrm{~kW}$ industrial motor (see Fig. 6) have been validated by Experimental Modal Analysis (using an external exciting force, a hammer) and FEM [17] (see Table I). Only the even circumferential modes have been considered because on that industrial motor, stator and rotor slots numbers are both even, generating only even spatial orders in the Maxwell exciting force harmonics for symmetry reasons.

Some validations with FEM, Experimental Modal Analysis and Operational Modal Analysis (using the internal exciting 


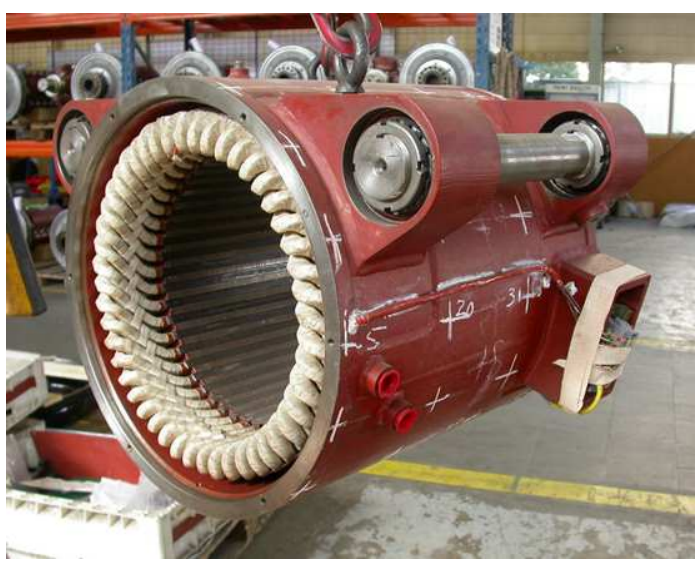

Fig. 6. Stator of industrial motor for Experimental Modal Analysis.

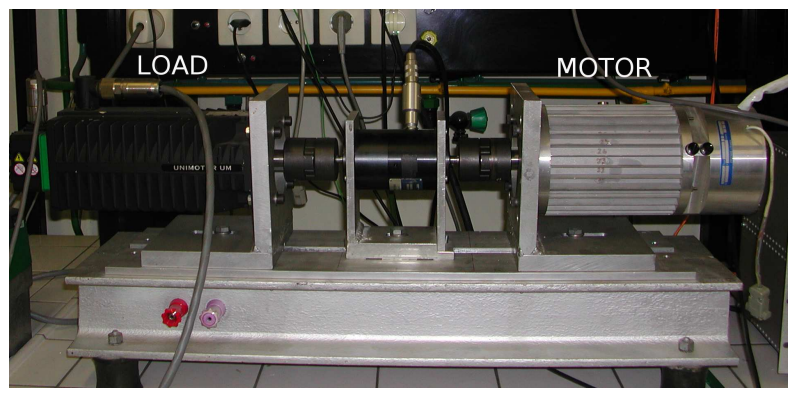

Fig. 7. Laboratory $700 \mathrm{~W}$ motor test-bench.
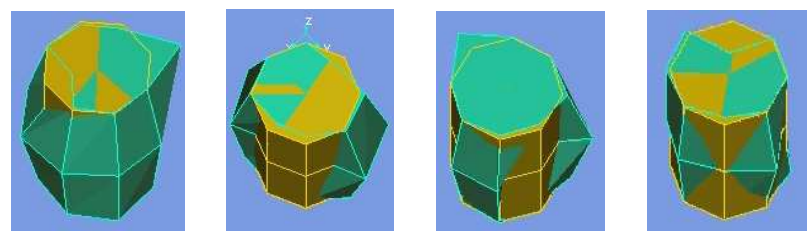

Fig. 8. Deflection shapes of some stator circumferential modes of the laboratory motor $(m=0$ : breathing mode, $m=2$ : elliptical mode, $m=3$ : 3-order elliptical mode, $m=4$ : 4-order elliptical mode).

\begin{tabular}{|c|c|c|c|}
\hline$m$ & DIVA & 2-D FEM & EMA full stator \\
\hline 0 & $3453(2.5)$ & 3642 & $3283(1.5)$ \\
2 & $719(1.3)$ & 699 & $616(2.16)+731(2.22)$ \\
4 & $3493(2.5)$ & 3200 & $3106(0.96)+3383(0.88)$ \\
\hline
\end{tabular}

TABLE I

STATOR NATURAL FREQUENCIES COMPUTATION (Hz) AND DAMPING COEFFICIENT (IN PARENTHESIS, IN \%) OF INDUSTRIAL MOTOR USING DIVA AND FEM (ANSYS).

\begin{tabular}{|c|c|c|c|c|}
\hline$m$ & 2-D FEM & EMA & DIVA & OMA \\
\hline 0 & 14656 & OR & 14860 & 14400 \\
1 & $X$ & 1200 & 1273 & 1234 \\
2 & 2364 & 2400 & 2485 & 2345 \\
3 & 6473 & 6100 & 6415 & 6370 \\
4 & 11898 & 11700 & 12065 & 11790 \\
\hline
\end{tabular}

TABLE II

STATOR NATURAL FREQUENCIES COMPUTATION (Hz) OF LABORATORY MOTOR USING DIFFERENT METHODS (OR: OUT OF RANGE, $\mathrm{X}$ : UNDEFINITE).

forces of the motor, i.e. magnetic forces) have been also carried on the small $700 \mathrm{~W}$ laboratory motor represented in Fig. 7.
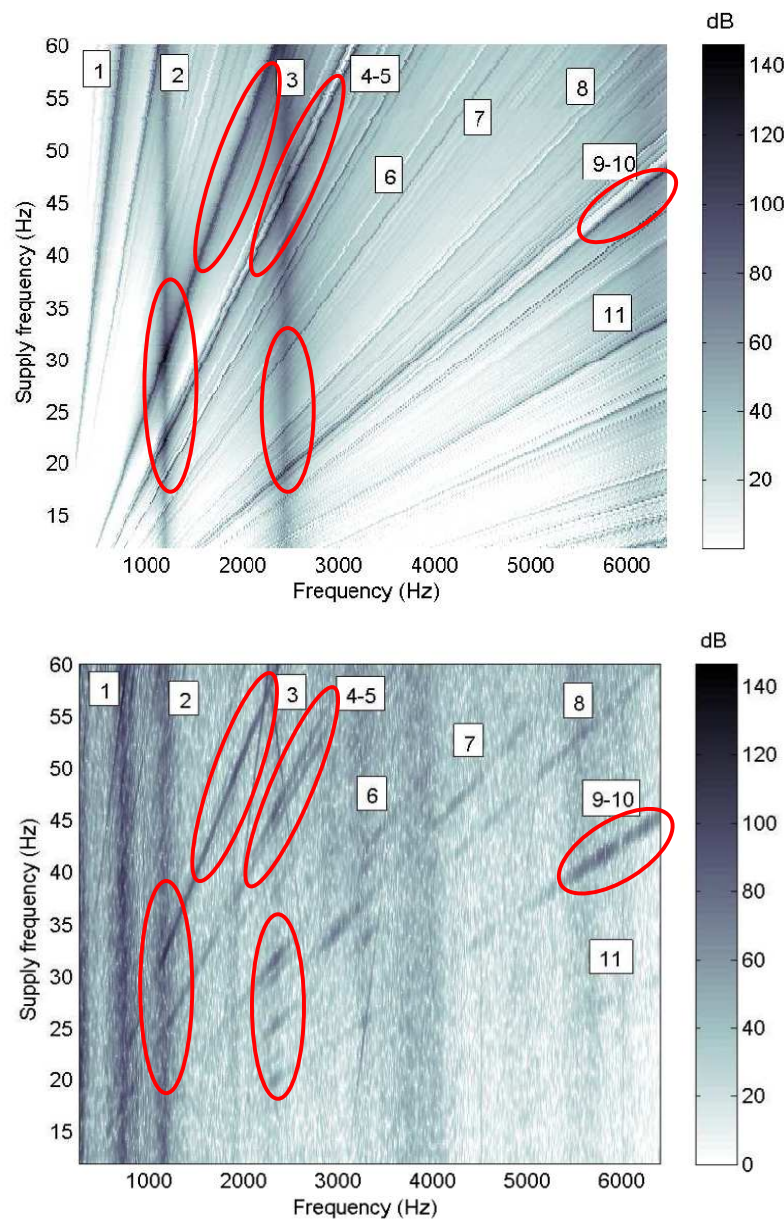

Fig. 9. Simulated (top) and experimental (bottom) acceleration spectrogram in sinusoidal case (laboratory motor, $f_{s}=12$ to $60 \mathrm{~Hz}$ ). An uncertainty exists on the experimental supply frequency as no tachometer probe could be used.

Results are displayed in Table II. The deflection shapes of the stator modes measured during the OMA are presented in Fig. 8. A mesh of accelerator sensors is used to determine deflection shapes (mode order and frequency) in three dimensions. This experimention does not show significative influence of axial behavior. Frequencies obtained by three dimensions OMA are closed ( \pm 5percent $)$ to two dimensions theoretical predictions. In that case, odd circumferential modes have been considered as the laboratory motor has some odd numbers of rotor and stator slots [11].

2) Vibration and sound power level: Some acceleration measurements have been done on laboratory motor at variable speed. In that case, measured acceleration spectra at each speed are compiled in a figure called a spectrogram. In a spectrogram (or a sonagram if sound is recorded), time or motor speed (which are generally proportional to the supply frequency) are reported in ordinates, frequencies are reported in abscissa, and the sound or vibration level is indicated with a color gradient. These spectrogram are run at constant flux in order to keep a constant magnetic excitation during starting phase.

Spectrogram Fig. 9, run from 12 to $60 \mathrm{~Hz}$, presents the comparison between measured and simulated vibration spectrogram on the (low noise when sinus fed) $700 \mathrm{~W}$ laboratory 
motor. We can see that in the lowest part of the spectrum, a high difference exists between DIVA and tests: it is mainly due to mechanical vibrations that are not modeled in DIVA. At higher frequencies $(\geq 500 \mathrm{~Hz})$, simulation predicts favorably the main vibrations (surrounded) as compared to experimentation. The parts that are amplified independently of motor speed (vertical lines) stand for the motor natural frequencies. We can see that in DIVA spectrogram, the mode 2 natural frequency around $2400 \mathrm{~Hz}$ is more amplified than in tests. However, the experimental response of a given natural frequency on a spectrogram highly depends on the position of the accelerometer (nodes or anti-nodes of the mode): the simulation gives an acceleration spectrum averaged over the stator circumference, whereas experiments give an acceleration spectrum on a particular point. In both figures, we can see that the main magnetic vibration lines are well predicted by DivA. The origin and the expressions of all these vibration lines (winding, slotting and saturation harmonics) is detailed in [18], [19]. Frequencies and spatial orders of main vibrations are presented in Table III.

\begin{tabular}{|c|c|c|}
\hline nb. & Frequency $f$ & Spatial order $m$ \\
\hline \hline 1 & $f_{s}\left(Z_{r}(1-s) / p+2\right)$ & -2 \\
2 & $f_{s}\left(2 Z_{r} / p-2\right)$ & -1 \\
3 & $f_{s}\left(4 Z_{r}(1-s) / p-2\right)$ & -1 \\
4 & $f_{s}\left(5 Z_{r}(1-s) / p\right)$ & -3 \\
5 & $f_{s}\left(5 Z_{r}(1-s) / p+2\right)$ & 1 \\
6 & $f_{s}\left(8 Z_{r}(1-s) / p-2\right)$ & 2 \\
7 & $f_{s}\left(9 Z_{r}(1-s) / p\right)$ & 0 \\
8 & $f_{s}\left(10 Z_{r}(1-s) / p+2\right)$ & -2 \\
9 & $f_{s}\left(13 Z_{r}(1-s) / p-2\right)$ & -1 \\
10 & $f_{s}\left(13 Z_{r}(1-s) / p\right)$ & 3 \\
11 & $f_{s}\left(18 Z_{r}(1-s) / p\right)$ & 0 \\
\hline
\end{tabular}

TABLE III

ChARACTERISATION OF MOTOR M1 $\left(Z_{s}=27, Z_{r}=21, p=2\right)$ PURE SLOTTING VIBRATION LINES.

After reliable prediction of vibrations on low noise laboratory motor, validations must be extended to noise on industrial motor. Fig. 10 shows an experimental and simulated sonagram of the $250 \mathrm{~kW}$ industrial motor run from 0 to $200 \mathrm{~Hz}$. Note that although the colorbars are the same, the scales are different as the experimental sonagram has a minimum ambient noise of $50 \mathrm{~dB}$, whereas simulated sonagram starts from $0 \mathrm{~dB}$. The main natural frequencies (vertical line) near $720 \mathrm{~Hz}$, which corresponds to the stator elliptical mode (cf. Table I), and the main magnetic lines (depending on supply frequency) are correctly predicted by DIVA. Major source of noise caused by coincidence of magnetic lines and mechanical resonance (near $50 \mathrm{~Hz}$ supply frequencies) is also well predicted (surrounded). The origin and the expressions of all these acoustic lines are detailed in [18], [20].

\section{APPLICATION}

On the ground of this simulation tool, a new $250 \mathrm{~kW}$ ALSTOM motor has been built by changing the rotor design: the numbers of rotor slots has been chosen to avoid resonances due to slotting harmonics [4] and saturation harmonics [21], and the rotor slot opening width has been fixed to reduce some
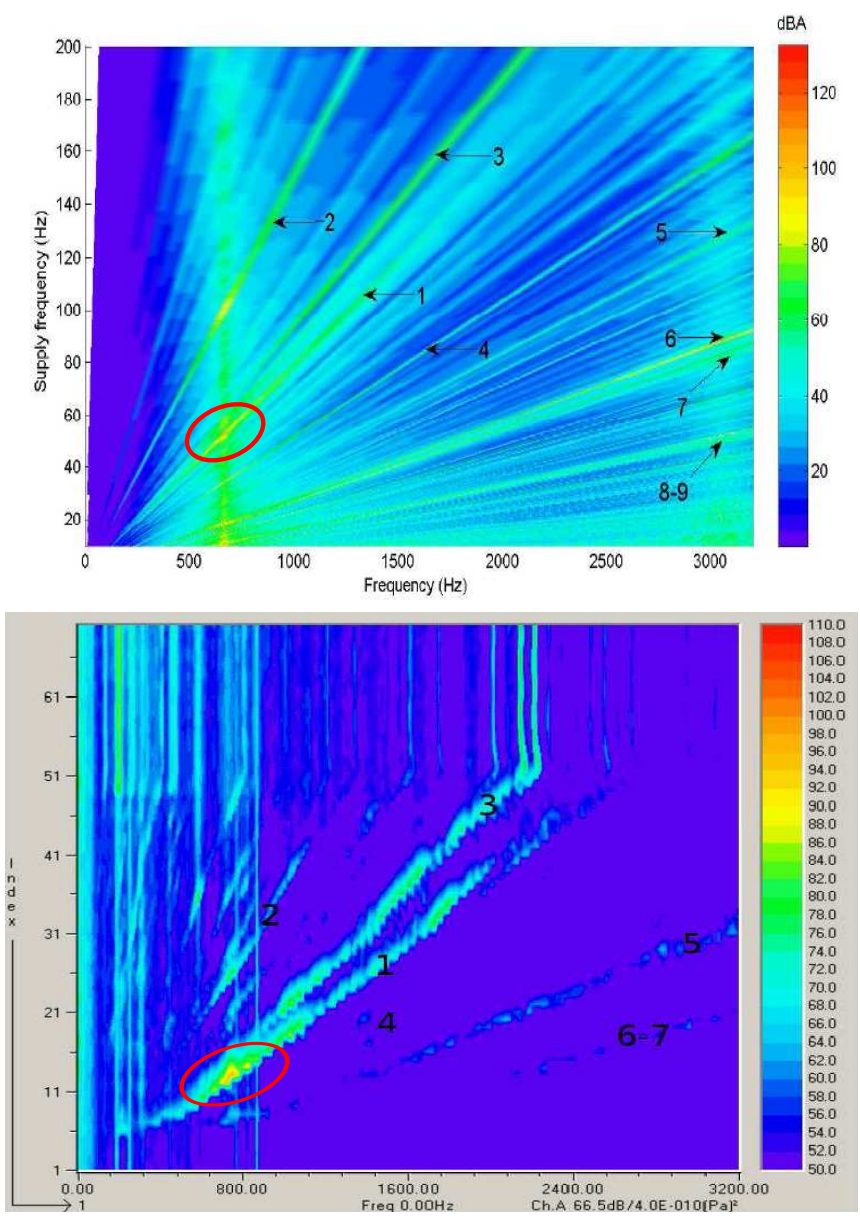

Fig. 10. Simulated (top) and experimental (bottom) sonagram on motor in sinusoidal no-load case. Note that experimental sonagram ordinates is time in seconds, as no tachometer probe was available, whereas simulated sonagram ordinates is $f_{s}$ in $\mathrm{Hz}$.

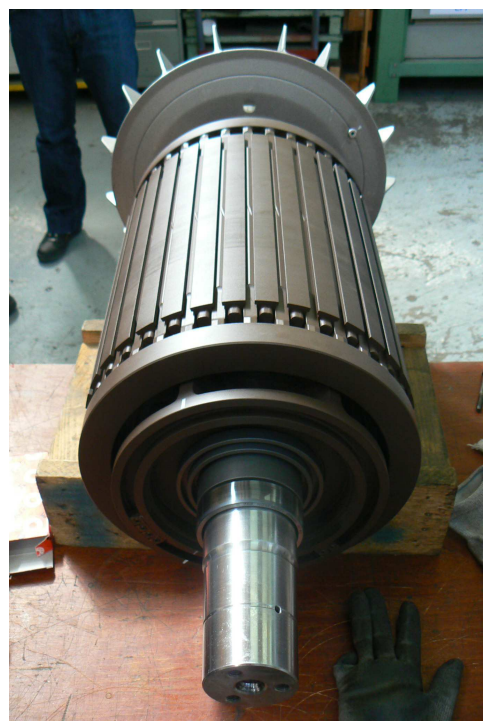

Fig. 11. New rotor of the industrial $250 \mathrm{~kW}$ motor. 


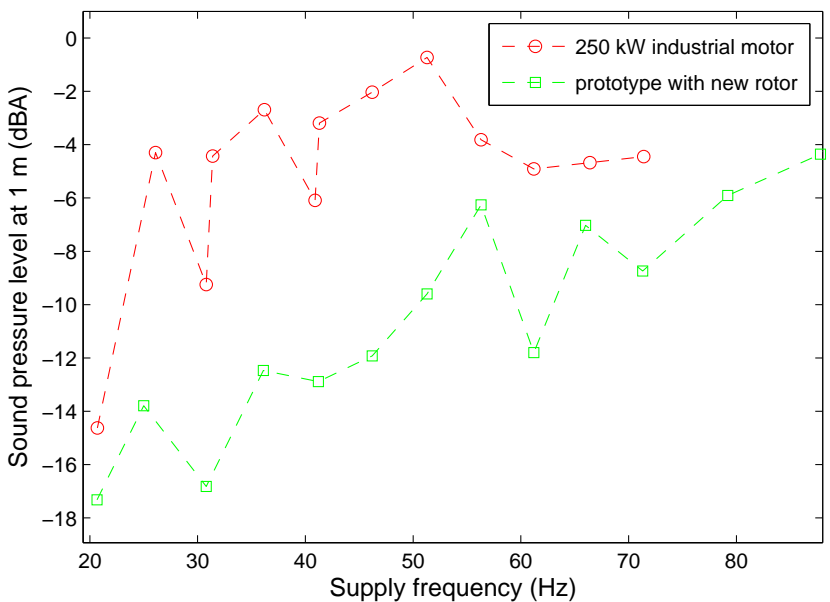

Fig. 12. Sound pressure level radiated by the new motor, compared to the initial $250 \mathrm{~kW}$ industrial motor, and its skewed rotor version(sinusoidal onload case).

magnetic force harmonics magnitude [22]. Fig. 11 shows this rotor prototype.

A $15 \mathrm{~dB}$ noise reduction was obtained during starting in off-load case (compared to a simulated $20 \mathrm{~dB}$ reduction [18]). The expected tendency is also well respected in on-load case with a $10 \mathrm{~dB}$ decrease as shown Fig.12. The simulation tool has therefore been successfully applied to drastically reduce the magnetic noise level in the whole speed range.

\section{CONCLUSION}

A fully analytical model of the induction machine, describing its electromagnetic and vibro-acoustic behavior, has been described. This model allows predicting the audible magnetic noise level radiated by the motor, and principal resonances occurring during starting or braking. The model has been validated at different stages, with both experiments and FEM, and on a wide power range (from $700 \mathrm{~W}$ to $250 \mathrm{~kW}$ ). This tool can be used for both designing new low-noise motors, and diagnose magnetic noise issues on existing motors. It is especially fast and accurate (a spectrogram going up to 20 $\mathrm{kHz}$ is obtained in a few minutes on a $2 \mathrm{GHz}$ laptop) without coupling computationally greedy numerical methods or using statistical energy method [23], [24].

This simulation tool has been applied to design a new 250 $\mathrm{kW}$ traction motor with a significant noise reduction.

\section{ACKNOWLEDGMENT}

The authors would like to thank the ADEME and VIBRATEC company who have partly supported this work.

\section{REFERENCES}

[1] W. Finley, M. Hodowanec, and W. Holter, "An analytical approach to solving motor vibration problems," in Proc. of the 46th Annual Petroleum and Chemical Industry Conference, 1999.

[2] S. Williamson and Y. Feng, "Slot-harmonic fields in closed-slot machines," IEEE Trans. on Ind. Appl., vol. 44, no. 4, pp. 1165 - 1171, July-aug 2008.
[3] S. Kreitzer, J. Obermeyer, and R. Mistry, "The effects of structural and localized resonances on induction motor performance," IEEE Trans. on Ind. Appl., vol. 44, no. 5, pp. 1367-1375, Sept-oct 2008.

[4] J. Le Besnerais, V. Lanfranchi, M. Hecquet, and P. Brochet, "Optimal slot numbers for magnetic noise reduction in variable-speed induction motors," 2009, submitted to IEEE Trans. on Mag.

[5] A. Belahcen, "Magnetoelasticity, magnetic forces and magnetostriction in electrical machines," Ph.D. dissertation, Helsinki University of Technology, Finland, Aug. 2004.

[6] P. Alger, Induction machines : their behaviour and uses. Gordon and Breach Science Publishers, 1970.

[7] P. Timar, Noise and vibration of electrical machines. Elsever, 1989.

[8] H. Jordan, Electric motor silencer - formation and elimination of the noises in the electric motors. W. Giradet-Essen editor, 1950.

[9] G. Bossio, C. D. Angelo, J. Solsona, G. Garcia, and M. Valla, "A 2-D model of the induction machine: an extension of the modified winding function approach," IEEE Trans. on Energy Conversion, vol. 19, no. 1, pp. 62-67, Mar. 2004.

[10] A. Hubert, "Contribution à l'étude des bruits acoustiques générés lors de l'association machines électriques - convertisseurs statiques de puissances - application à la machine asynchrone," Ph.D. dissertation, Université des Technologies de Compiègne, France, Dec. 2000.

[11] J. Le Besnerais, V. Lanfranchi, M. Hecquet, P. Brochet, and G. Friedrich, "Acoustic noise of electromagnetic origin in a fractional-slot induction machine," COMPEL, vol. 27, no. 5, pp. 1033 - 1052, Feb. 2008.

[12] S. J. Yang, Low noise electrical motors. Oxford: Clarendon Press, 1981.

[13] P. Timar and J. Lai, "Acoustic noise of electromagnetic origin in an ideal frequency-converter-driven induction motor," IEE Proc. on Electr. Power Appl., vol. 141, no. 6, pp. 341-346, Nov. 1994.

[14] J. Gieras, C. Wang, and J. Lai, Noise of polyphase electric motors. CRC Press, Dec. 2005.

[15] M. Anwar and I. Hussain, "Radial force calculation and acoustic noise prediction in switched reluctance machines," IEEE Trans. on Ind. App., vol. 36, no. 6, pp. 1589-1597, 2000.

[16] K. Maliti, "Modelling and analysis of magnetic noise in squirrel-cage induction motors," Ph.D. dissertation, Stockholm, 2000.

[17] A. Ait-Hammouda, "Prédimensionnement et étude de sensibilité vibroacoustique de machines courant alternatif et vitesse variable," $\mathrm{Ph} . \mathrm{D}$. dissertation, Université des Sciences et des Technologies de Lille, France, Mar. 2005

[18] J. Le Besnerais, "Reduction of magnetic noise in PWM-supplied induction machines - low-noise design rules and multi-objective optimisation," Ph.D. dissertation, Ecole Centrale de Lille, France, Nov. 2008.

[19] J. Le Besnerais, V. Lanfranchi, M. Hecquet, P. Brochet, and G. Friedrich, "Characterisation of the radial vibration force and vibration behaviour of a PWM-fed fractional-slot induction machine," IET Electric Power Applications, Feb. 2009.

[20] J. Le Besnerais, V. Lanfranchi, M. Hecquet, and P. Brochet, "Characterization of the audible magnetic noise emitted by traction motors in railway rolling stock," in Proc. of the INTERNOISE conference, Shanghai, China, Oct. 2008.

[21] J. Le Besnerais, V. Lanfranchi, M. Hecquet, G. Lemaire, E. Augis, and P. Brochet, "Charaterization and reduction of magnetic noise due to saturation in induction machines," IEEE Trans. on Mag., accepted for publication.

[22] J. Le Besnerais, V. Lanfranchi, M. Hecquet, R. Romary, and P. Brochet, "Optimal slot opening width for magnetic noise reduction in induction motors," IEEE Trans. on En. Conv., accepted for publication.

[23] C. Wang and J. Lai, "Sound power radiated from an inverter driven induction motor. part 3: statistical energy analysis," IEE Proc. on Electr. Power Appl., vol. 152, no. 3, pp. 619-626, May 2005.

[24] K. Delaere, M. Iadevaia, W. Heylen, P. Sas, K. Hameyer, and R. Belmans, "Statistical energy analysis of acoustic noise and vibration for electric motors: Transmission from air gap field to motor frame," vol. 3, 1999. 